\title{
Usefulness of Reduced Port Surgery for Left Colon Cancer
}

\author{
MASAYOSHI NAKANISHI ${ }^{1}$, YOSHIAKI KURIU ${ }^{1}$, YASUTOSHI MURAYAMA ${ }^{1}$, \\ TOMOHIRO ARITA ${ }^{1}$, HIROSHI ITO ${ }^{2}$, TOSHIYUKI KOSUGA ${ }^{1}$, RYO MORIMURA $^{1}$, \\ HIROTAKA KONISHI $^{1}$, SYUHEI KOMATSU ${ }^{1}$, ATSUSHI SHIOZAKI ${ }^{1}$, HISASHI IKOMA ${ }^{1}$, \\ DAISUKE ICHIKAWA $^{1}$, HITOSHI FUJIWARA ${ }^{1}$, KAZUMA OKAMOTO $^{1}$ and EIGO OTSUJI ${ }^{1}$ \\ ${ }^{1}$ Division of Digestive Surgery, Department of Surgery, and ${ }^{2}$ North Medical Center, \\ Kyoto Prefectural University of Medicine, Kyoto, Japan
}

\begin{abstract}
Aim: Although laparoscopic surgery has made minimally invasive treatment available for colon cancer, various innovations aimed at developing even more minimally invasive treatment modalities have been reported in recent years. Needlescopic surgery, in which forceps with a small-diameter shaft are used to safely reduce invasiveness without increasing surgeons' stress, has been reported. We introduced the reduced-port surgery (RPS) technique by using needle forceps for the treatment of sigmoidal colon cancer and cancer of the rectosigmoidal region, with the aim of safely reducing invasiveness while maintaining curability. Patients and Methods: The subjects of this study were patients with sigmoidal colon and rectosigmoidal cancer who underwent laparoscopic resection between January 2012 and December 2014. The patients were divided into a conventional multiport surgery (MPS) group and an RPS group for comparison and analysis. Results: No significant difference was observed in the operative time, volume of blood loss, incidence of postoperative complications, especially anastomotic leak, intestinal obstruction, and surgical site infection. The length of postoperative hospital stay was significantly shorter in the RPS group. Conclusion: Without compromising safety and curability, RPS can reduce not only the number, but also the size of incisions, and make even more minimally invasive surgery feasible. Because this procedure is relatively easy to introduce to young surgeons, we consider it to be useful.
\end{abstract}

Laparoscopic surgery for colon cancer was first reported by Jacobs et al. in 1991 (1). Subsequently, its usefulness for advanced colon cancer has been reported in various

Correspondence to: Masayoshi Nakanishi, 602-8566, 465, Kajiicho, Kamigyo-ku, Kyoto, Japan. Tel: +81 752515527, Fax: +81 752515522, e-mail:mnakan@koto.kpu-m.ac.jp

Key Words: Reduced port surgery, colon cancer. randomized controlled trials, and the procedure is currently widely performed $(2,3)$.

Although laparoscopic surgery has made minimally invasive treatment available for colon cancer, various innovations aimed at developing even more minimally invasive treatment modalities have been reported in recent years. In particular, single-port surgery is a procedure in which all maneuvers are performed through a single small abdominal incision, and this procedure was first performed for colorectal resection by Bucher et al. in 2008 (4). Since then, it has been reported that minimally invasive surgery can be safely performed with this procedure (5). However, this procedure can be stressful for surgeons due to forceps interference and other maneuvers.

Meanwhile, needlescopic surgery, in which forceps with a small-diameter shaft are used to safely reduce invasiveness without increasing surgeons' stress, has also been reported to be beneficial (6).

We introduced the reduced-port surgery (RPS) technique by using needle forceps for the treatment of sigmoidal colon cancer and cancer of the rectosigmoidal region at our Department, with the aim of safely reducing invasiveness while maintaining curability. Here we explain this surgical procedure together with its short-term outcomes.

\section{Patients and Methods}

The study included patients with sigmoidal colon and rectosigmoidal cancer who underwent laparoscopic resection between January 2012 and December 2014. The patients were divided into the conventional multiport surgery (MPS) group and the RPS group for comparison and analysis. According to the Japanese Classification of Colorectal Carcinoma (7), patients in whom the main bulk of the tumor was located at the lower margin of the second sacral vertebra or below were included.

MPS was performed with five ports, and a $12 \mathrm{~mm}$ port was inserted into the right lower abdomen. In RPS, a lap protector and an EZ access were attached to the small midline incision. A 2-mm port was inserted into the left lower abdomen, a $5 \mathrm{~mm}$ port in the right lower abdomen, and a $3 \mathrm{~mm}$ port in the right lateral abdomen. 
Table I. Patients' background data

\begin{tabular}{lccc}
\hline Characteristic & MPS & RPS & $p$-Value \\
\hline Gender (male/female), $\mathrm{n}$ & $28 / 27$ & $10 / 16$ & 0.34 \\
Median age (range), years & $64(43-84)$ & $68.5(49-83)$ & 0.67 \\
Median BMI (range), $\mathrm{kg} / \mathrm{m}^{2}$ & $21.3(14.4)-36.0$ & $23.1(17.3-31.4)$ & 0.10 \\
Median tumor size (range), mm & $36(0-90)$ & $25(0-60)$ & 0.32 \\
Median preoperative CEA (range), $\mathrm{ng} / \mathrm{ml}$ & $3.2(0.9-3784.5)$ & $2.3(0.5-4602$ & 0.40 \\
\hline
\end{tabular}

MPS: Multiport surgery; RPS: reduced port surgery; BMI: body mass index; CEA: carcinoembryonic antigen.

Table II. Characteristics of operations performed.

\begin{tabular}{lccc}
\hline Characteristic & MPS & RPS & $p$-Value \\
\hline Median surgical time (range), min & $230(74-597)$ & $201(160-347)$ & 0.06 \\
Median blood loss (range), ml & $5(0-269)$ & $5(0-58)$ & 0.64 \\
Median lymph nodes harvested (range), $\mathrm{n}$ & $18(3-97)$ & $21(9-31)$ & 0.44 \\
Median metastatic lymph nodes (range), $\mathrm{n}$ & $0(0-12)$ & $0(0-15)$ & 0.52 \\
Surgical site infection, yes/no, n & $8 / 45$ & $4 / 22$ & 1.00 \\
Ileus, yes/no, $\mathrm{n}$ & $2 / 47$ & $0 / 26$ & 1.00 \\
Leakage, yes/no, $\mathrm{n}$ & $2 / 53$ & $10.5(6-22)$ & 1.00 \\
Median postoperative hospital stay (range), days & $12(9-77)$ & & 0.05 \\
\hline
\end{tabular}

MPS: Multiport surgery; RPS: reduced port surgery.

Endo Relief forceps (Hope Denshi Co., Ltd.) were inserted from the $2 \mathrm{~mm}$ port, and 3-mm forceps (Karl Storz-Endoskope) were inserted from the $3 \mathrm{~mm}$ port (Figure 1). The abdomen after RPS is shown in Figure 2, and each forceps is shown in Figure 3.

In both procedures, $5 \mathrm{~mm}$ flexible scopes (Olympus Co., Ltd.) were used. To perform intestinal resection, an automatic suture device was inserted from the $12 \mathrm{~mm}$ port in the right lower abdomen in MPS and the $12 \mathrm{~mm}$ port in the umbilical incision in RPS.

To compare the differences between MPS and RPS, JMP 12 statistical software (SAS Institute, Cary, North Carolina, USA) was used to perform the chi-square test and Wilcoxon signed-rank test.

\section{Results}

As shown in Table I, no significant difference was observed in the background factors. Moreover, concerning the surgical factors, no significant difference was observed in the operative time or volume of blood loss, whereas the number of dissected lymph nodes was comparable between the two groups. As shown in Table II, no significant difference was observed in the incidence of postoperative complications, especially of anastomotic leak, intestinal obstruction, and surgical site infection. The length of postoperative hospital stay was significantly shorter in the RPS group.

\section{Discussion}

Laparoscopic surgery has highlighted the great merit of minimally invasive procedures for the surgical treatment of colorectal cancer (1). In recent years, laparoscopic surgery has also been widely performed for advanced colon cancer in response to the results of large-scale trials $(2,3,8,9)$. Moreover, in Japan, the number of patients undergoing laparoscopic surgery for colorectal cancer is increasing yearly; at the same time, the procedure is also frequently performed for advanced colorectal cancer. Among these cases, attempts to further reduce invasiveness have also been reported (5).

Single-port surgery is performed through a small abdominal incision through which three ports are inserted. It is a minimally invasive surgical procedure, and its short-term outcomes have shown its usefulness (10-12). In addition, a previous report also indicated that the long-term outcomes of this procedure are comparable to those of conventional MPS (13). However, it is also reported that, depending on the form of the pelvic wall, the addition of one port is often necessary (14). Furthermore, there are problems, such as the frequent interference between several pairs of forceps due to a lack of adequate space between them, and the difficulty in obtaining a good view as a result of the noninsertion of forceps handled by assistants. For these reasons, only skilled surgeons can safely perform this procedure while maintaining curability.

Meanwhile, surgery with forceps having a small diameter has also been reported $(6,15)$. As these tools have gradually been improved in terms of stiffness and operability, extremely useful forceps are available at present. We insert Endo Relief (Hope Denshi Co., Ltd.) from a 2-mm port into the left lower abdomen. Although this model of forceps has a shaft with a 2.4 


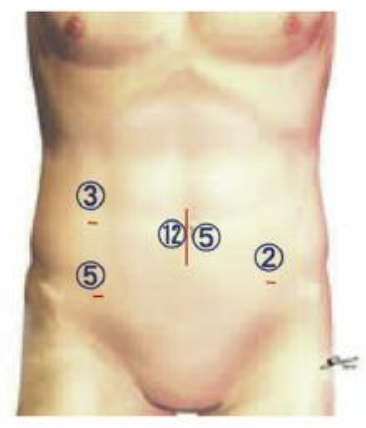

RPS

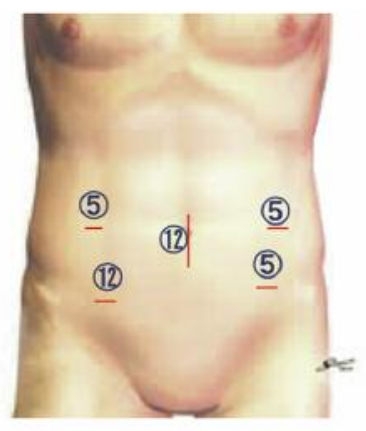

MPS
Figure 1. The left image shows the incisions for port insertion in reduced port surgery (RPS), and the right image shows those used in multiport surgery (MPS). The numbers indicate the size of wounds $(\mathrm{mm})$.

$\mathrm{mm}$ diameter, the tip section is the same size as that of the 5 $\mathrm{mm}$ forceps. The tip section is attached to Endo Relief after the shaft is inserted through a port. Because Endo Relief is slightly less stiff, it is not appropriate for use by surgeons. We consider that it is appropriate for assistants to use the forceps because this model allows them to hold large tissue. We use the $3 \mathrm{~mm}$ forceps manufactured by Karl Storz-Endoskope for insertion from the $3 \mathrm{~mm}$ port into the right lateral abdomen. This model of forceps is stiffer and has a slightly smaller tip section than Endo Relief. Delicate maneuvers can be performed with the Karl Storz-Endoskope forceps. However, caution is warranted because, owing to the smaller tip section, tissue is likely to be damaged when held with the forceps and strongly pulled. Thus, there is a risk of damaging the tissue beyond the visual field when assistants use the $3 \mathrm{~mm}$ forceps. We consider that it is better for surgeons to use the forceps with their left hand.

Another difference between MPS and RPS is that the length of the port in the right lower abdomen is $5 \mathrm{~mm}$ in RPS. To perform intestinal resection with the conventional procedure, an automatic suture device is inserted from the $12 \mathrm{~mm}$ port into the right lower abdomen; however, with RPS, the device is inserted from the $12 \mathrm{~mm}$ port into the midline incision. We consider that this manner confers an advantage for RPS because the length of the $12 \mathrm{~mm}$ port incision in the right lower abdomen, which results in complaints of severe pain, is reduced to 5 mm.Concerning long-term outcomes, it has been reported that even single-incision laparoscopic surgery is comparable to MPS. Our study also shows no difference between the MPS and RPS groups at this point. Because of the small number of cases and the short follow-up period, further careful follow-up is needed.

\section{Conclusion}

Without compromising safety and curability, RPS can reduce not only the number but also the size of incisions, and make

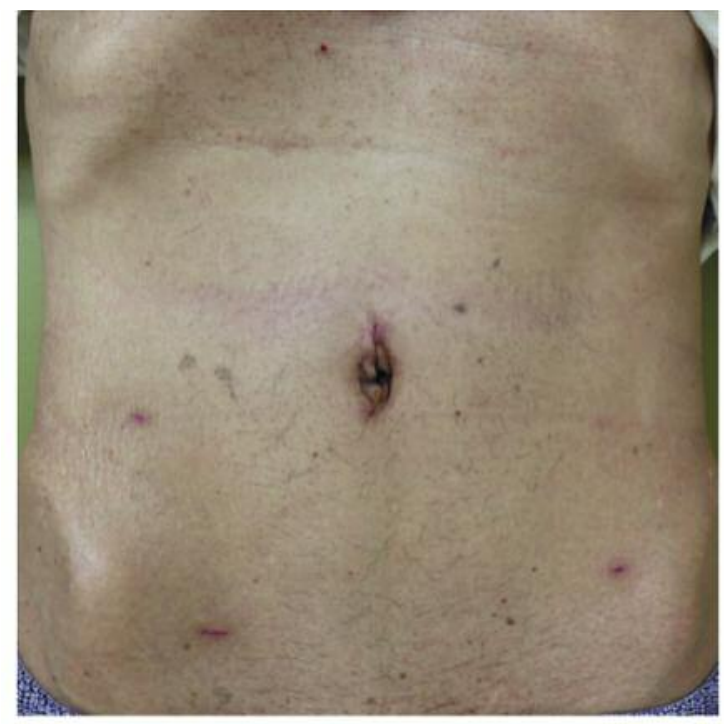

Figure 2. The incision sites at 1 month after reduced port surgery reduced port surgery. For forceps with a small diameter, the incision is unnoticeable.
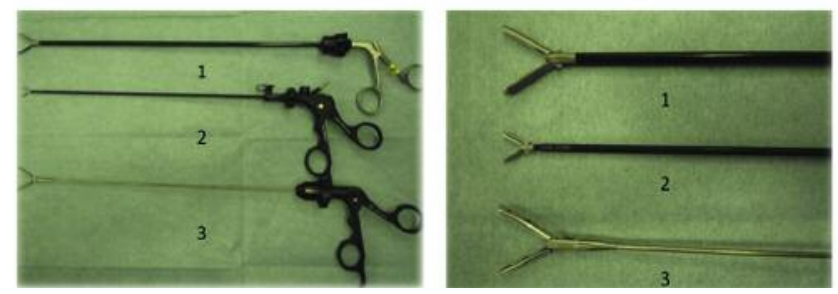

Figure 3. A: Gross view of the instruments used in surgery in this study. B: Close up of tips of instruments shown in A. 1: Conventional $5 \mathrm{~mm}$ forceps. 2: $3 \mathrm{~mm}$ Forceps. 3: Endo Relief with a $2.4 \mathrm{~mm}$-diameter shaft. Endo Relief is composed of a tip section of the same size as that of the $5 \mathrm{~mm}$ forceps and a shaft with an extremely small diameter.

even more minimally invasive surgery feasible. Because this procedure is relatively easy to introduce to young surgeons, we consider it to be useful.

\section{References}

1 Jacobs M, Verdeja JC and Goldstein HS: Minimally invasive colon resection (laparoscopic colectomy). Surg Laparosc Endosc 1(3): 144-150, 1991.

2 Lacy AM, Garcia-Valdecasas JC, Delgado S, Castells A, Taura $\mathrm{P}$, Pique JM and Visa J: Laparoscopy-assisted colectomy versus open colectomy for treatment of non-metastatic colon cancer: A randomised trial. Lancet 359(9325): 2224-2229, 2002.

3 Buunen M, Veldkamp R, Hop WC, Kuhry E, Jeekel J, Haglind E, Pahlman L, Cuesta MA, Msika S, Morino M, Lacy A and Bonjer HJ: Survival after laparoscopic surgery versus open surgery for colon cancer: Long-term outcome of a randomised clinical trial. Lancet Oncol 10(1): 44-52, 2009. 
4 Bucher P, Pugin F and Morel P: Single port access laparoscopic right hemicolectomy. Int J Colorectal Dis 23(10): 1013-1016, 2008.

5 Takemasa I, Sekimoto M, Ikeda M, Mizushima T, Yamamoto H, Doki $\mathrm{Y}$ and Mori M: Video. Transumbilical single-incision laparoscopic surgery for sigmoid colon cancer. Surg Endosc 24(9): 2321, 2010.

6 Mukai T, Fukunaga Y, Ueno M, Nagayama S, Fujimoto Y, Konishi T, Akiyoshi T, Ono R and Yamaguchi T: Needlescopic surgery for left-sided colorectal cancer. Int J Colorectal Dis 29(12): 1501-1505, 2014.

7 Rectum JSfCotCa: Japanese classification of colorectal carcinoma. Kanehara Co., Ltd.: Tokyo, Japan, 2009.

8 Guillou PJ, Quirke P, Thorpe H, Walker J, Jayne DG, Smith AM, Heath RM and Brown JM: Short-term endpoints of conventional versus laparoscopic-assisted surgery in patients with colorectal cancer (mrc clasicc trial): Multicentre, randomised controlled trial. Lancet 365(9472): 1718-1726, 2005.

9 Fleshman J, Sargent DJ, Green E, Anvari M, Stryker SJ, Beart RW Jr., Hellinger M, Flanagan R Jr., Peters W and Nelson H: Laparoscopic colectomy for cancer is not inferior to open surgery based on 5-year data from the Cost Study Group Trial. Ann Surg 246(4): 655-662; discussion 662-654, 2007.

10 Rink AD, Vestweber B, Paul C and Vestweber KH: Singleincision laparoscopic surgery for colorectal malignancy-results of a matched-pair comparison to conventional surgery. Int $\mathbf{J}$ Colorectal Dis 30(1): 79-85, 2015.
11 Suzuki O, Nakamura F, Kashimura N, Nakamura T, Takada M and Ambo Y: A case-matched comparison of single-incision versus multiport laparoscopic right colectomy for colon cancer. Surg Today 46(3): 297-302, 2016.

12 Tei M, Wakasugi M and Akamatsu H: Comparison of short-term surgical results of single-port and multi-port laparoscopic rectal resection for rectal cancer. Am J Surg 210(2): 309-314, 2015.

13 Katsuno G, Fukunaga M, Nagakari K, Yoshikawa S, Azuma D and Kohama S: Short-term and long-term outcomes of singleincision versus multi-incision laparoscopic resection for colorectal cancer: A propensity-score-matched analysis of 214 cases. Surg Endosc, 2015.

14 Hamabe A, Takemasa I, Uemura M, Nishimura J, Mizushima T, Ikeda M, Yamamoto H, Sekimoto M, Doki Y and Mori M: Feasibility of single-port laparoscopic surgery for sigmoid colon and rectal cancers and preoperative assessment of operative difficulty. J Gastrointest Surg 18(5): 977-985, 2014.

15 Tagaya $\mathrm{N}$ and Kubota K: Reevaluation of needlescopic surgery. Surg Endosc 26(1): 137-143, 2012. 